\title{
Why should neurologists start to be interested in Arboviruses?
}

\author{
Por que os neurologistas deveriam começar a se interessar por Arbovirus?
}

Abelardo Q. C. Araújo 1,2

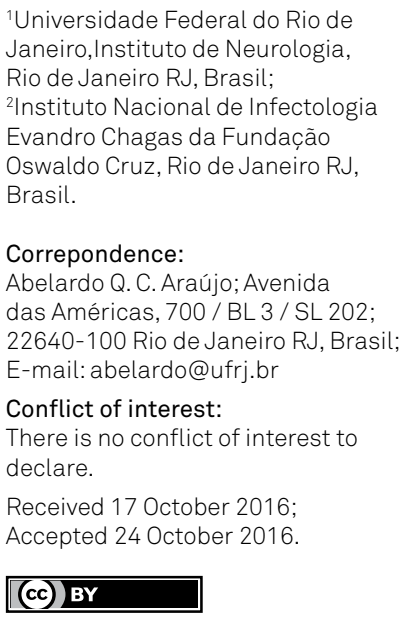

'Universidade Federal do Rio de Janeiro,Instituto de Neurologia, Rio de Janeiro RJ, Brasil;

${ }^{2}$ Instituto Nacional de Infectologia Evandro Chagas da Fundação Oswaldo Cruz, Rio de Janeiro RJ, Brasil.

Correpondence:

Abelardo Q. C. Araújo; Avenida das Américas, 700 / BL 3 / SL 202;

22640-100 Rio de Janeiro RJ, Brasil;

E-mail:abelardo@ufrj.br

Conflict of interest:

There is no conflict of interest to

declare.

Received 17 October 2016; Accepted 24 October 2016.

\section{(c) BY}

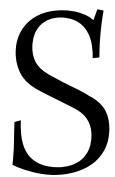

ystemic viral infections are common, however symptomatic involvement of the nervous system in viral infections is rare.

Arthropod-borne viruses (arboviruses) are transmitted to hosts during blood feeding of mosquitos, ticks, biting flies, mites and nits. While the majority of these viruses are neither neuroinvasive or neuropathogenic to man there are several members of many arboviruses families that can cause serious neurological diseases ${ }^{1}$.

In the present edition of Arquivos de Neuropsiquiatria, Pinheiro et al. ${ }^{2}$ make a didactical review on the neurological manifestations of Zika (ZIKV) and Chikungunya (CHIKV) viruses. Both viruses are endemic not only in Brazil but seem also to be spreading throughout the Americas.

From this Review we learn that, although members of different arbovirus families (ZIKV being a flavivirus and CHIKV a togavirus) they share many similarities both in terms of their general clinical manifestations as well as in their ability to induce primary or secondary neurological damage.

Although ZIKV has caught most of the attention of the lay ${ }^{3}$ and scientific press ${ }^{4}$ due to the increasing number of cases of microcephaly (Congenital ZIKV syndrome) and Guillain-Barré syndrome (GBS) associated with previous infection by ZIKV, one should not forget that CHIKV is also spreading in the country and is also able to invade the nervous system and cause neurological diseases ${ }^{5,6}$.

The public health and economic implications of arboviruses outbreaks cannot be minimized. Globally, dengue virus (DENV) fever is still the most common arboviral disease, with $40 \%$ of the world's population living in areas with DENV transmission. Of the estimated 390 million infections and 100 million cases annually, a small proportion of these cases progress to severe DENV disease. DENV is another virus endemic in Brazil and is well known for its ability to produce nervous system damage?

The emergency of an epidemic of ZIKV associated microcephaly is of great concern for countries with relatively high birth rates. Medical, economical and psychological burden suffered by families are worsened by the whole health system, which cannot adequately deal with all the short and long term requirements of the current situation. Also, ethical and social implications have to be taken into account particularly in countries in which abortion is restricted to very specific situations or even totally prohibited. The consequences of a GBS outbreak are also worrying because it brings along an unbearable overload of both public and private health systems, which may not be able to respond quickly and efficiently to an increased population of patients needing continued hospitalization support and specific and expensive treatments.

In a country heavily infested by Aedes sp. mosquitos, the common vector for DENV, ZIKV and CHIKV, Brazilian neurologists should take the lead in the battle against the ominous consequences of these infectious. Knowing their neurological manifestations and keeping a high index of suspicion when faced with a patient with a recent history of fever, rash and arthralgias is the starting point to fight against these emerging and reemerging diseases. 


\section{References}

1. Salimi H, Cain MD, Klein RS. Encephalitic arboviruses: emergence, clinical presentation, and neuropathogenesis. Neurotherapeutics. 2016;13(3):514-34. doi:10.1007/s13311-016-0443-5

2. Pinheiro TJ, Guimarães LF, Silva, MTT, Soares CN. Neurological manifestations of Chikungunya and Zika infections. Arq Neuropsiquiatr. 2016;74(11):937-943. doi:10.1590/0004-282X20160138

3. Araujo AQ, Silva MT, Araujo AP. 2016: the year of Zika. OupBlog; 2016 [cited 2016 Aug 8]. Available from: http://blog.oup. com/2016/08/2016-year-of-zika/

4. Araujo AQ, Silva MT,Araujo AP.Zika virus-associated neurological disorders: a review. Brain. 2016;139(8):2122-30. doi:10.1093/brain/aww158
5. Chandak NH, Kashyap RS, Kabra D, Karandikar P, Saha SS, Morei SHet al. Neurological complications of Chikungunya virus infection. Neurol India. 2009;57(2):177-80. doi:10.4103/0028-3886.51289

6. Tournebize P, Charlin C, Lagrange M. [Neurological manifestations in Chikungunya: about 23 cases collected in Reunion Island]. Rev Neurol (Paris). 2009;165(1):48-51. French. doi:10.1016/j.neurol.2008.06.009

7. Verma R, Sahu R, Holla V. Neurological manifestations of dengue infection: a review. J Neurol Sci. 2014;346(1-2):26-34. doi:10.1016/j.jns.2014.08.044 